\title{
MODELING THE MICROSTRUCTURE OF SLAG-BLENDED CEMENTS USING ARTIFICIAL NEURAL NETWORK
}

\author{
H.I. Ahmed \\ Lecturer of Properties and Strength of Materials, Civil Eng. Dept, Faculty of Engineering, Beni-Suef University, Egypt.
}

\begin{abstract}
This paper proposes the artificial neural network (ANN) as a numerical technique to simulate the microstructure of slagblended cements. The ANN model adopted in this research consists of three neurons in the input layer which represent contents of both water-cooled slag (WCS) and OPC and WCS finenesses and three neurons in the output layer which represent calcium silicate hydrate $(\mathrm{C}-\mathrm{S}-\mathrm{H})$, Portalndite $(\mathrm{CH})$, and capillary porosity. Back Propagation algorithm was employed for the ANN training in which a Tansig function was used as the nonlinear transfer function. Thermogravimetric analysis and de-sorption approaches were performed to study the microstructure of the different OPC/slag pastes. The results obtained from experiments agreed with that predicted by $\mathrm{ANN}$, where, the prediction ANN model gives very close estimates of $\mathrm{C}-\mathrm{S}-\mathrm{H}, \mathrm{CH}$, and capillary porosity of OPC/WCS pastes. Therefore, the developed ANN model can be used as an alternative approach to evaluate the microstructure of slag-blended cements.
\end{abstract}

KEYWORDS: Artificial Neural Network (ANN); Slag; Capillary Porosity; Calcium Silicate Hydrate (C-S-H).

\section{INTRODUCTION}

Classical studies of the microstructure of cement paste and concrete have been largely done using various techniques [1]. techniques has divided these into two categories, direct and indirect methods. The direct methods give the image of the microstructure in terms of the size and shape of the phases relative to each others in space. The common techniques in this category are optical microscopy, electron microscopy,

Corresponding author. E-mail address:

Beni-suef university, Egypt image analysis and back scattered electron microscopy. On the other hand, indirect methods provide information about the average size and distribution of sizes of some or all the phases. Some common techniques in this category are the mercury intrusion porosimetry, ethanol adsorption, water absorption and thermogravimetric analysis [2].

Recently, some researches on the artificial neural network (ANN) in data processing are introduced in the field of durability and they are very efficient compared with simple regression method obtained from experimental data [3]. In area of research on concrete, a neural network technique is mainly applied to mixture design $[4,5]$, strength evaluation $[6,7]$ and reaction of hydration [8].

An artificial neural network (ANN) is a data processing system consisting of a large number of simple, interconnected computational elements referred to as "neurons" in an architecture inspired by the structure of the cerebral cortex of the brain [9]. The ANN technique uses very simple computational operations (e.g. addition, multiplication, and logic operations) to solve complex problems that are ill-defined and possess high degrees of nonlinearity. 
The most important element in every ANN architecture is the neuron which is similar to the biological neurons. It is considered as a cell with a built-in activation function connected to other neurons by a set of connections. Main elements of an Artificial Neural Network are the input layer which includes the input neurons corresponding to parameters which are assumed to affect the outcome of the phenomenon, output layer which includes the output neuron(s) which represent(s) the solution of the problem, hidden layer(s) located between the input layer and the output layer and connection weights. Prediction accuracy of the network depends on its interconnected weights. A network usually performs the following three sequential tasks [10]; a) Input variables fed to the input layer, b) Processing of information within the hidden layer, c) Production of outputs at the output layer.

In this research a back-propagation neural network (BPNN) was developed to simulate the microstructure of different hardened OPC pastes made with WCS. Although other neural network architectures, such as the generalized regression neural network (GRNN) and genetic adaptive nets (GAN), could provide faster training, BPNN was selected because of its proven mapping capabilities and widespread application in civil engineering [11].

In order to collect comparative data, an experimental program was conducted in this research considering various conditions such as (WCS) finenesses $\left(0.4,1.8,3.0\right.$, and $\left.4.0 \mathrm{~m}^{2} / \mathrm{g}\right)$ and
WCS contents $(0 \%, 15 \%, 20 \%$, and $25 \%$ by mass of OPC). Furthermore, thermo-gravimetric analysis and de-sorption approaches were performed to study the microstructure of the WCS-blended cements.

\section{SCOPE OF THE RESEARCH}

The ultimate objective of this research work is to provide a reliable numerical technique capable of evaluating the microstructure of WCS-blended cements. The specific objectives were as follows:

1. To investigate impacts of WCS content and WCS fineness on the hydration and hence porosity of WCS-blended cements using ANN.

2. To determine the most appropriate functions and architecture to be adopted in ANN model.

3. To compare between experimental data and ANN model predictions in order to determine the efficacy and accuracy of the developed ANN modes.

\section{EXPERIMENTAL}

\section{Materials, Slag Preparation and Mix Proportions}

The standard materials used were ordinary Portland cement (OPC) and water-cooled slag (WCS). OPC was provided by Beni-suef Portland Cement Company and WCS was supplied from the Iron and Steel Company, Helwan, Egypt. The chemical analysis and surface areas of OPC and WCS are listed in Table 1. 
Table 1 Chemical analysis and surface areas of OPC and WCS.

\begin{tabular}{|c|c|c|c|c|c|c|c|c|c|c|}
\hline & $\mathrm{SiO}_{2}$ & $\mathrm{Al}_{2} \mathrm{O}_{3}$ & $\mathrm{Fe}_{2} \mathrm{O}_{3}$ & $\mathrm{CaO}$ & $\mathrm{MgO}$ & $\mathrm{Na}_{2} \mathrm{O}$ & $\mathrm{K}_{2} \mathrm{O}$ & $\mathrm{SO}_{3}$ & LOI & $\begin{array}{c}\text { Surface } \\
\text { area, } \mathrm{m}^{2} / \mathrm{g}\end{array}$ \\
\hline $\mathrm{OPC}$ & 21.3 & 3.58 & 5.05 & 63.48 & 1.39 & 0.26 & 0.22 & 2.05 & 2.57 & 0.37 \\
\hline WCS & 44.05 & 13.78 & 1.73 & 36.2 & 0.3 & 0.6 & 0.15 & 2.07 & 0.23 & $\begin{array}{c}0.4,1.8,3, \\
\text { and } 4\end{array}$ \\
\hline
\end{tabular}

them above saturated salt solution of barium chloride

The water-cooled slag (WCS) was produced by rapid quenching of slag in water. The water-cooled slag was oven dried at $105{ }^{\circ} \mathrm{C}$ for 24 hours to remove the moisture, which occurred during the granulation process, using an electrical oven with digital monitoring. The grinding of WCS was performed using a laboratory ball mill with maximum capacity of $10 \mathrm{~kg}$. The surface area of the slag was measured volumetrically from the adsorption of the nitrogen gas at the liquid nitrogen temperature $\left(-195.8{ }^{\circ} \mathrm{C}\right)$ using a BET volumetric apparatus. The surface areas of the produced slag were $0.4,1.8,3$, and $4 \mathrm{~m}^{2} / \mathrm{g}$.

Thirty OPC/WCS paste mixes were prepared, using various WCS contents $(0,15,20$ and $25 \%$, by weight of OPC), various WCS finenesses $\left(0.4,1.8,3\right.$, and $\left.4 \mathrm{~m}^{2} / \mathrm{g}\right)$ and constant Water-to-binder ratio $(\mathrm{w} / \mathrm{b})$ of 0.5 .

\section{Preparation of Test Samples}

Mixing the cement paste was carried out manually, till complete homogeneity of mixes was achieved. Circular cement paste discs of thickness $5 \mathrm{~mm}$ and $50 \mathrm{~mm}$ diameter were then prepared for microstructure analysis (using thermo-gravimetric and de-sorption approaches). After casting, all molded samples were covered with plastic sheets for 24 hours and then immersed in water curing tank $(20 \pm$ $2^{\circ} \mathrm{C}$ ) till the age of testing.

\section{Test Techniques}

\section{De-sorption test}

This test was used to estimate the amount of interconnected pores (capillary porosity), as described by Ngala et al [12] and Parrott et al [13]. The saturated specimens specified for this study were dried at $90.7 \%$ relative humidity by placing contained in a desiccator until a near-constant sample weight was obtained. The weight loss on drying was then converted to volume fraction of the bulk paste. This particular capillary porosity corresponds to pores wider than about $30 \mathrm{~nm}$. The Full details of the techniques and procedures of this test are described in [12-14]. The average capillary porosity results were calculated using five specimens.

\section{Thermo-gravimetric analysis}

The hardened cement paste specimens specified for this study were subjected to thermo-gravimetric analysis (TGA), by monitoring the $\%$ weight loss (\% decomposition) that takes place as a result of raising temperature according to a defined regime. Previous studies found that calcium silicate hydrate $(\mathrm{C}-\mathrm{S}-\mathrm{H})$ and calcium hydroxide $(\mathrm{CH})$ decompose at a range of temperature of 110 to $250{ }^{\circ} \mathrm{C}$ and 450 to $600{ }^{\circ} \mathrm{C}$, respectively $[15,16]$. Therefore, the amount of C-S-H and $\mathrm{CH}$ can be expressed as a function of the difference in the \% weight loss occurred at these defined range of temperatures [16].

Following this concept, the hardened cement paste samples were subjected to a wide range of temperature increase and the weights were recorded at $110,250,450$ and $600^{\circ} \mathrm{C}$. The $\%$ weight loss due to decomposition of $\mathrm{C}-\mathrm{S}-\mathrm{H}$ and $\mathrm{CH}$ were consequently estimated for all tested samples. The average results of these abovementioned parameters for five samples were calculated.

\section{NETWORK ARCHETICTURE}


The design of the ANN model requires identifying the network architecture (i.e. number of input neurons, output neurons, hidden layers, and neurons in each hidden layer) and the network settings (activation function and learning rate). The network architecture adopted in this research consists of five neurons in the input layer, which represents content of OPC, content of water-cooled slag (WCS), fineness of WCS, the \% weight loss due to decomposition of both $\mathrm{C}-\mathrm{S}-\mathrm{H}$ and $\mathrm{CH}$, and one neuron in the output layer, which represents the capillary porosity.

The optimal number of hidden layers was determined by considering the trade off between generalization and mapping capabilities of the neural network. Basically, the choice is limited to one or two hidden layers because of the ability of these networks to approximate any nonlinear function and map any unknown relationships between the input and output variables [17]. Four-layer ANN's (i.e. two hidden layers) have superior fitting capabilities over threelayer ANN's (i.e. one hidden layer), however, three-layer ANN's are computationally faster and have better generalization capabilities [18]. Also, it was reported that 95\% of the working applications were based on three-layer networks with only few exceptions [19]. That is why a three-layer ANN was selected for the present application.

For the network settings, activation functions are applied to bind the network input and output of the different layers to a specific range that the network can efficiently handle. This range is usually scaled between 0 and 1 or -1 and 1 . Different activation functions are provided by the used simulator, such as sigmoid, threshold, step, linear, and Gaussian functions. The selection of the most appropriate function is also a matter of trial-and-error. A scaling range between 0 and 1 with the logistic sigmoid activation function were found to be the best settings for the present application. The learning rate, which identifies the amount of adjustments to connection weights during training, was determined based on the network performance.

The learning rate was set to change from 1.0 to 0.1 according to the percentage of correct predictions (from
$100 \%$ to $0 \%$ ) in each training cycle. This set up is efficient since it results in high learning rates in the early training cycles, and low learning rates in advanced training cycles, which is required to fine tune network weights and achieve network stability.

\section{RESULTS AND DISCUSSION}

\section{HYDRATION OF SLAG-BLENDED CEMENT}

The results obtained from both ANN and thermogravimetric analysis for the different hardened OPC pastes made with various WCS contents are shown in Figs. 1 and 2. It is obvious from the results shown in Fig. 1 that the amount of C-S-H of all WCS mixes was reasonably higher compared to that of the OPC control mix. The amount of increase in the \% decomposition of CSH reaches about 14 , 21 , and $29 \%$, when 15,20 , and $25 \%$ WCS replacement levels were adopted. While, as seen in Fig. 2, the amount of $\mathrm{CH}$ of all WCS mixes was reasonably lower compared to that of the pure OPC control mix. The amount of decrease in the $\%$ decomposition of $\mathrm{CH}$ reaches about 17,33 , and $50 \%$, when 15, 20, and 25\% WCS replacement levels were adopted The increase in of $\mathrm{CSH}$ and the reduce of $\mathrm{CH}$ may be due to the pozzolanic reaction of WCS which combines with $\mathrm{CH}$ resulted from the hydration of $\mathrm{OPC}$, to form a fine $\mathrm{CSH}[20]$.

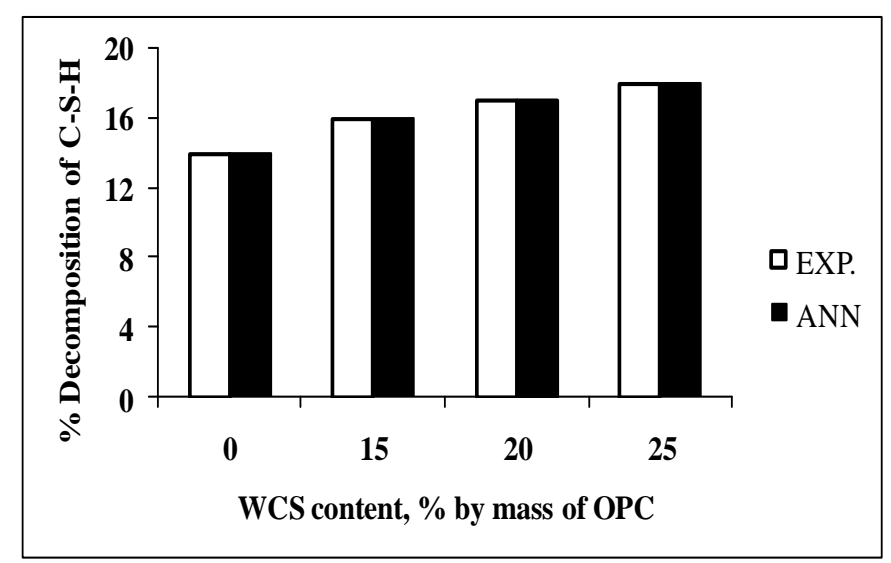

Fig. $1 \%$ Decomposition of C-S-H of OPC/WCS pastes with constant WCS fineness $\left(0.4 \mathrm{~m}^{2} / \mathrm{g}\right)$ 


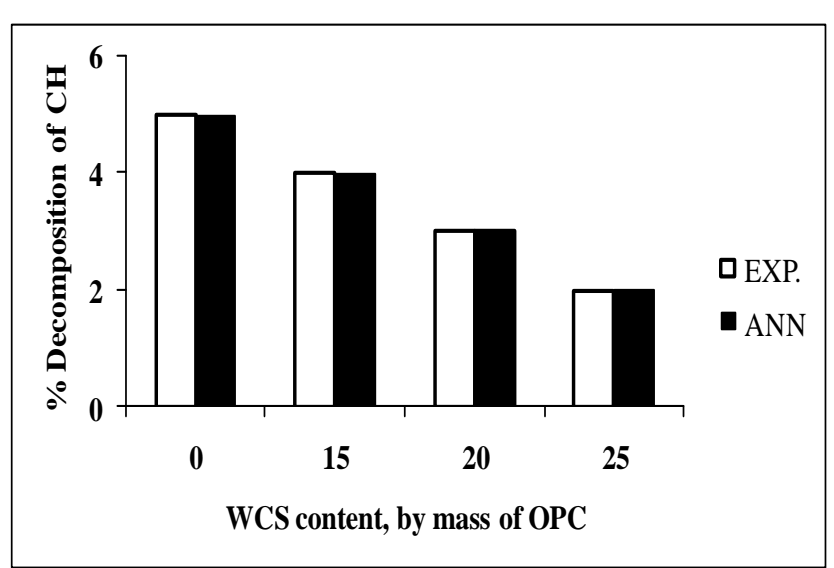

Fig. $2 \%$ Decomposition of CH of OPC/WCS pastes with constant WCS fineness $\left(0.4 \mathrm{~m}^{2} / \mathrm{g}\right)$

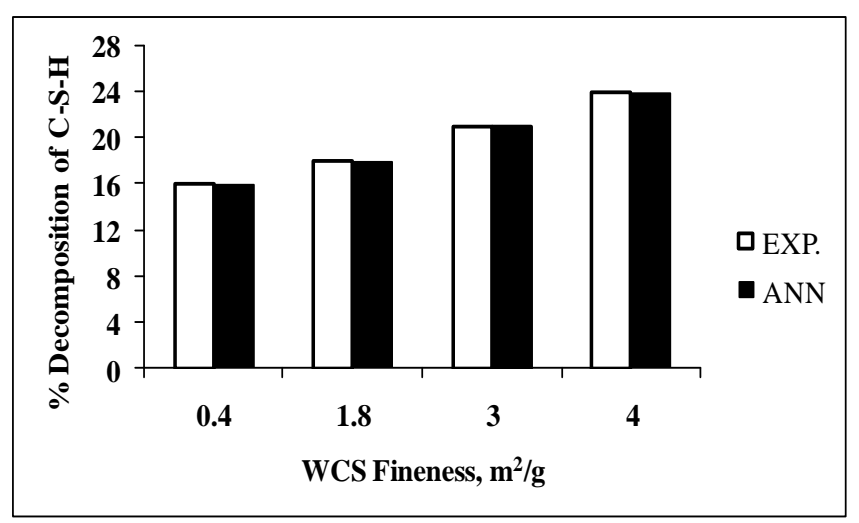

Fig. $3 \%$ Decomposition of C-S-H of OPC/WCS pastes with constant WCS content (15\%, by mass of OPC)

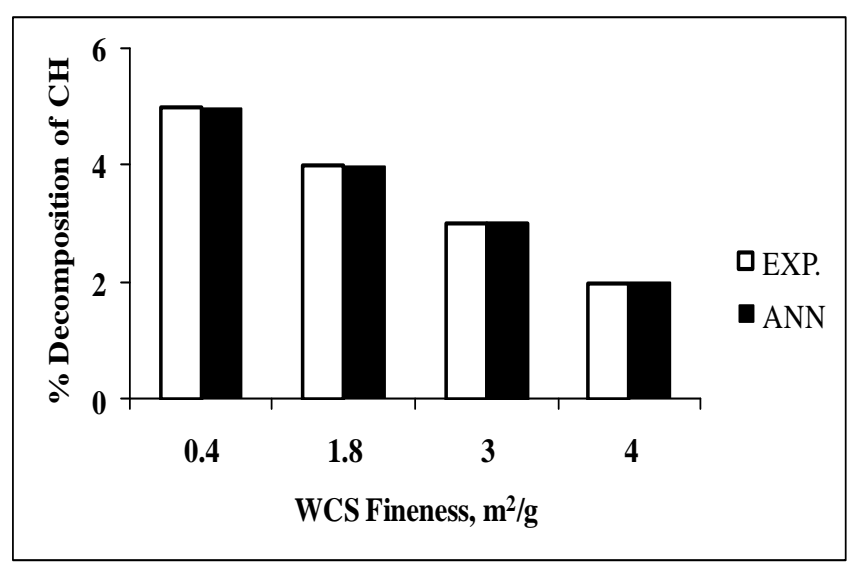

Fig. $4 \%$ Decomposition of $\mathrm{CH}$ of OPC/WCS pastes with constant WCS content ( $15 \%$, by mass of OPC)

The results obtained from both ANN and thermogravimetric analysis for the different hardened OPC pastes made with various WCS finenesses $\left(0.4,1.8,3\right.$, and $\left.4 \mathrm{~m}^{2} / \mathrm{g}\right)$ are shown in Figs. 3 and 4. As seen in Fig. 3, the amount of
$\mathrm{CSH}$ is significantly increased with increasing fineness of WCS. The amount of increase in the \% decomposition of $\mathrm{CSH}$ reaches about $14,29,50$, and $71 \%$, when $0.4,1.8,3$, and $4 \mathrm{~m}^{2} / \mathrm{g}$ finenesses were adopted, respectively. While, as seen in Fig. 4, the amount of $\mathrm{CH}$ is significantly decreased with increasing WCS fineness. The amount of decrease in the $\%$ decomposition of $\mathrm{CH}$ reaches about 17, 33, 50, and $67 \%$, when $0.4,1.8,3$, and $4 \mathrm{~m}^{2} / \mathrm{g}$ finenesses were adopted, respectively.

Moreover, there is a significant agreement between the results obtained from experiments and those predicted by ANN when the microstructures of 15,20 , and $25 \%$ slag mixes regarded.

\section{POROSITY OF SLAG-BLENDED CEMENT}

The results of capillary porosity obtained from the Desorption test and those predicted by the ANN model for the different hardened OPC pastes made with different contents of WCS $(0,15,20$, and $25 \%$, by mass of OPC), various WCS finenesses $\left(0.4,1.8,3\right.$, and $\left.4 \mathrm{~m}^{2} / \mathrm{g}\right)$ and constant $\mathrm{w} / \mathrm{b}$ of 0.5 are illustrated in Figs. (5-9). It is generally apparent from the results obtained from both ANN model and experimental data that the capillary porosity is reduced with increasing both the content and fineness of WCS. The amount of decrease in capillary porosity of the different OPC / WCS pastes compared to the control OPC mix is listed in Table 2.

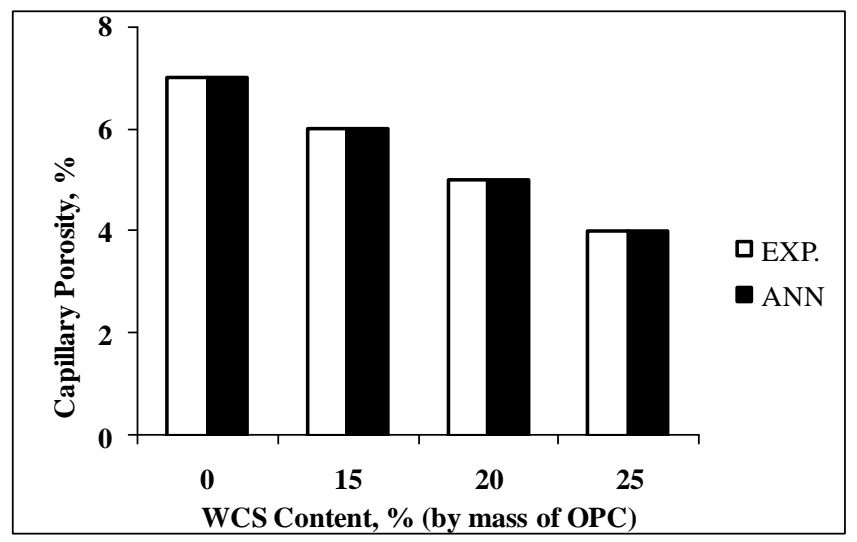

Fig. 5 Capillary porosity of OPC/WCS pastes with constant WCS fineness $\left(0.4 \mathrm{~m}^{2} / \mathrm{g}\right)$ 
Proc. of the Third Intl. Conf. on Advances in Civil, Structural and Construction Engineering - CSCE 2015 Copyright (C) Institute of Research Engineers and Doctors, USA .All rights reserved.

ISBN: 978-1-63248-079-8 doi: 10.15224/ 978-1-63248-079-8-62

Table 2 Amount of decrease in both $\mathrm{CH}$ and capillary porosity and increase in C-S-H of different OPC / WCS pastes.

\begin{tabular}{|c|c|c|c|c|}
\hline $\begin{array}{l}\text { WCS fineness, } \\
\mathrm{m}^{2} / \mathrm{g}\end{array}$ & $\begin{array}{c}\text { WCS replacement } \\
\text { level, } \% \\
\text { by mass of OPC }\end{array}$ & $\begin{array}{c}\text { increase in C-S-H } \\
\text { compared to the control } \\
\text { OPC mix, } \%\end{array}$ & $\begin{array}{c}\text { decrease in } \mathrm{CH} \\
\text { compared to the } \\
\text { control OPC mix, \% }\end{array}$ & $\begin{array}{l}\text { decrease in capillary } \\
\text { porosity compared to the } \\
\text { control OPC mix, } \%\end{array}$ \\
\hline \multirow{3}{*}{0.4} & 15 & 14 & 17 & 14 \\
\hline & 20 & 21 & 33 & 29 \\
\hline & 25 & 29 & 50 & 43 \\
\hline \multirow{3}{*}{1.8} & 15 & 29 & 33 & 29 \\
\hline & 20 & 36 & 50 & 43 \\
\hline & 25 & 43 & 67 & 58 \\
\hline \multirow{3}{*}{3.0} & 15 & 50 & 50 & 43 \\
\hline & 20 & 57 & 67 & 50 \\
\hline & 25 & 64 & 75 & 64 \\
\hline \multirow{3}{*}{4.0} & 15 & 71 & 67 & 57 \\
\hline & 20 & 79 & 80 & 71 \\
\hline & 25 & 86 & 88 & 81 \\
\hline
\end{tabular}

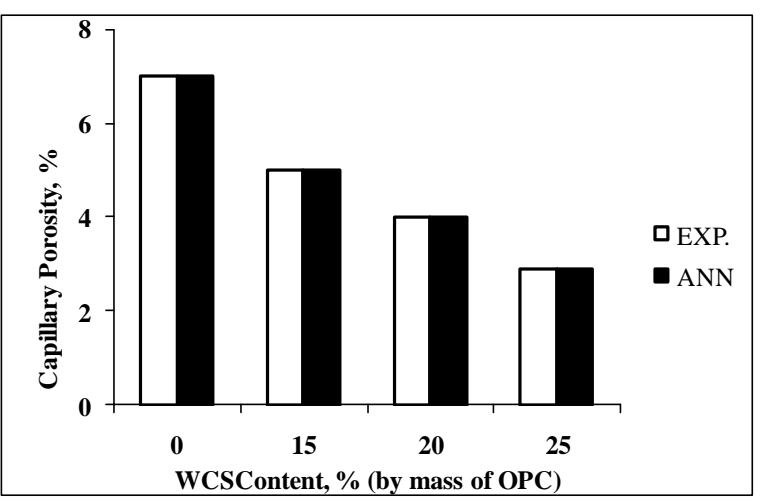

Fig. 6 Capillary porosity of OPC/WCS pastes with constant WCS fineness $\left(1.8 \mathrm{~m}^{2} / \mathrm{g}\right)$

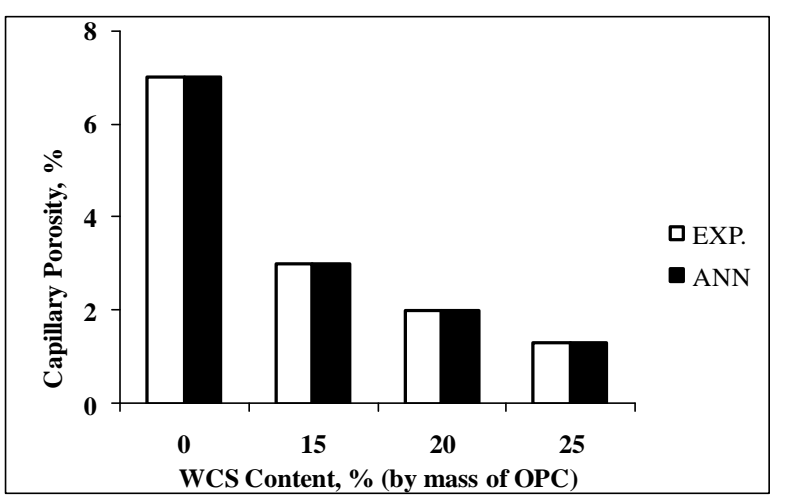

Fig. 8 Capillary porosity of OPC/WCS pastes with constant WCS fineness $\left(4.0 \mathrm{~m}^{2} / \mathrm{g}\right)$

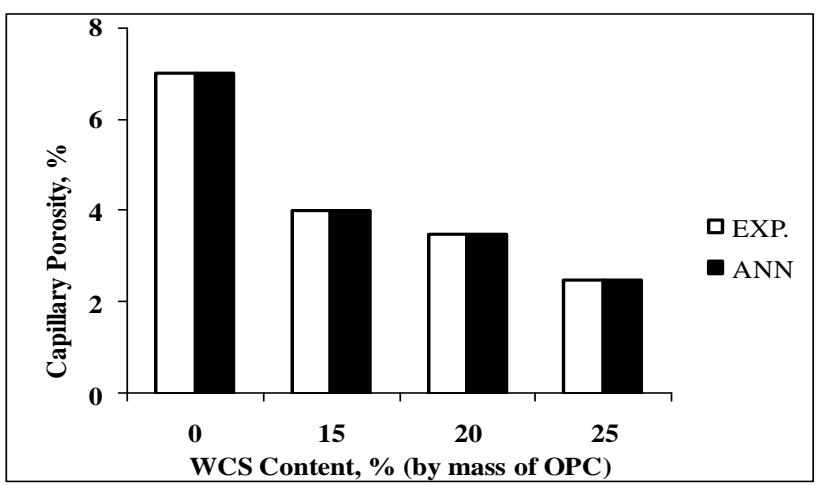

Fig. 7 Capillary porosity of OPC/WCS pastes with constant WCS fineness $\left(3.0 \mathrm{~m}^{2} / \mathrm{g}\right)$

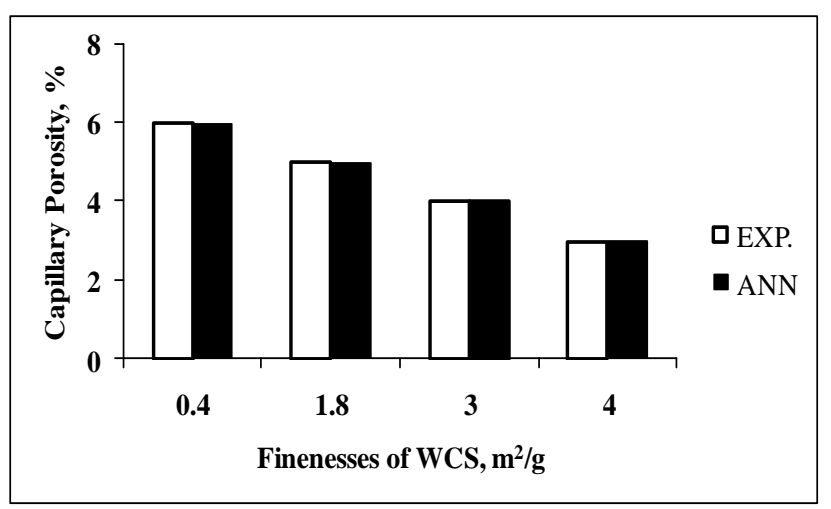

Fig. 9 Capillary porosity of OPC/WCS pastes with constant content of WCS (15\%, by mass of OPC) 
The decrease in the capillary porosity as a result of increasing WCS content is attributed to the increasing of CS-H phase and the decreasing of $\mathrm{CH}$ phase, see Figs (10-11). Moreover, the decrease in the capillary porosity as a result of increasing WCS fineness is attributed to the surface area of the slag particles exposed for the pozzolanic reaction, where, the finer the slag particles, the larger the surface area available for the calcium hydroxide to react with and hence the more pozzolanic reaction may be occurred. Consequently, a higher amount of CSH can be produced, which in turn would fill the unoccupied spaces within the paste matrix and then reduces the amount of continuous pores (capillary pores) [21].

\section{CONCLUSIONS}

The main conclusions of this study can be summarized as follows:

1. The research results obtained from both ANN model and experimental program demonstrate that both $\mathrm{CH}$ and capillary porosity of different hardened OPC pastes made with WCS decreases with increasing both fineness and content of WCS.

2. Comparison between experimental data and ANN model predictions has proven that there was a high correlation between the capillary porosity obtained from the de-sorption test and that predicted by ANN model, where, the prediction ANN model gives very close estimates of capillary porosity of OPC/WCS pastes. Therefore, the developed ANN model can be used as an alternative approach to evaluate the capillary porosity.

3. The results indicated that the methodology described using Backpropagation Artificial Network is a useful, powerful tool not only for accurately predicting capillary porosity, but also to identifying correlations between output and inputs.

4. Three-layer ANN's have the ability to approximate any nonlinear function and map any unknown relationships between the input and output variables.

\section{ACKNOWLEDGMENTS}

The author would like to express his gratitude towards professor Osama Hodhod for discussion and help provided.

\section{REFERENCES}

1. P.J.M. Monteiro, A.B. Kirchheim, S. Chae, P. Fischer, A.A. MacDowell, E. Schaible, and H.R. Wenk, " Characterizing the nano and micro structure of concrete to improve its durability". Cement and Concrete Composites, Vol. 31, No. 7, 2009, pp. 577-584.

2. H.I. Ahmed, " Predicting the chloride ingress process inside blended cement concrete using artificial neural networks", Ph.D. Thesis, Cairo University, Cairo, Egypt, 2014,149 pp.

3. O.A. Hodhod and H.I. Ahmed, "Developing an artificial neural network model to evaluate the chloride diffusivity in high performance concrete". HBRC Journal, Vol. 9, Isuue 1, 2013, pp. 15-21.

4. I.-C. Yeh, Modeling slump flow of concrete using second-order regressions and artificial neural networks, Cement and Concrete Research, Vol. 37, No. 4, 2007, pp. 474-480.

5. J.-Z. Wang, H.-G. Ni, J.-Y. He, The application of automatic acquisition of knowledge to mix design of concrete, Cement and Concrete Research, Vol. 29, No. 12, 1999, pp. 1875-1880

6. J.A. Stegemann, N.R. Buenfeld, Prediction of unconfined compressive strength of cement paste with pure metal compound additions, Cement and Concrete Research 32 (6) (2002) 903-913.

7. I.-C. Yeh, Modeling of strength of highperformance concrete using artificial neural networks, Cement and Concrete Research 28 (12) (1998) 1797-1808.

8. K.B. Park, T. Noguchi, J. Plawsky, Modeling of hydration reactions using neural networks to predict the average properties of cement paste, Cement and Concrete Research 35 (9) (2005) 1676-1984.

9. L. Fausett, "Fundamentals of neural networks: architectures, and applications", 1994. Prentice Hall, Upper Saddle River, NJ, USA.

10. Y.M. NAJJAR, and I.A. BASHEER, "Utilizing computational neural networks for evaluating the permeability of compacted clay liners, " Geotechnical and Geological Engineering, (1996a), 14 (3), pp. 193-212.

11. O. Moselhi, T. Hegazy, and P. Fazio, (1991), "Neural networks as tools in construction. " J. Construction Engrg. \& Management, ASCE, 117(4), 606-625.

12. V.T. Ngala, C.L. Page, L.J. Parropp, and S.W, Yu, "Diffusion in cementitious materials: II. Further investigation of chloride and oxygen diffusion in well-cured OPC and OPC/30\%PFA pastes", 
Cement and Concrete Research, Vol. 25, No. 4, pp. 819-826, 1995.

13. L.J. Parrott, "Variation of water absorption rate and porosity with depth from an exposed concrete surface: Effect of exposure conditions and cement type", Cement and Concrete Research, Vol. 22, No. 6, pp. 1077-1088, 1992.

14. J.F. Young, "Humidity control in the laboratory using salt solutions - A review", Journal of Applied Chemistry, Vol. 17, pp. 241-245, 1967.

15. A.I. Ramachandran, "Application of different thermal analysis in cement chemistry", Pub. Chemical Publishing Company, London, 1969.

16. A.A. Rahman, and F. P., Glasser, "Comparative studies of the carbonation of hydrated cements", Advances in Cement Research, Vol. 2, No. 6, pp. 49-54, 1989.

17. K. Hornik, M. Stinchcombe, and H. White, "Multilayer feed forward networks are universal approximators". Neural Networks 2 (5), 1989, pp. 359-366.

18. S. Tamura, and M. Tateishi, "Capabilities of fourlayered feed-forward neural networks: four layers versus three". IEEE Trans. on Neural Networks, 8(2), 1997, pp. 251-255

19. P. Simpson, "Neural Networks Theory, Technology, and Applications". 1996 IEEE, NY.

20. ACI COMMITTEE 233R, "Ground granulated blast furnace slag as a cementitious constituent in concrete", American Concrete Institute Manual of Concrete Practice (Detroit, Michigan), 16 pp, 1995.

21. Lim and Wee, "Autogenous shrinkage of ground granulated blast-furnace slag concrete", ACI Material Journal, Vol. 97, No. 5, pp. 586-593, 2000. 